\title{
7 Anhang
}

\section{Anhang A: Liste der untersuchten Affixe}

Deutsch (nach Duden 2016: 702, 719, 734 f., 762 f., 773)

Präfixe:

a-, an-, anti-, be-, de-, des-, durch-, ent-, er-, erz-, ge-, hinter-, im-, in-, inter-,

kon-, miss-, prä-, re-, trans-, über-, ultra-, um-, un-, unter-, ur-, ver-, wider-, zer-

Suffixe:

-abel, -age, -al, -ant, -anz, -ar, -är, -at, -bar, -chen, -e, -ei, -el, -ell, -em, -en, -end, -ent, -enz, -er, -erie, -ern, -es, -est, -eur, -fach, -haft, -halber, -heit, -ie, -ier, -ig, -ik, -in, -ion, -isch, -ismus, -ist, -ität, -iv, -keit, -lein, -ler, -lich, -ling, -los, -mäßig, -n, -ner, -nis, -oid, -or, -os, -ös, -s, -sam, -schaft, -st, -t, -tum, -ung, -ur, -wärts, -weg, -wegen, -weise

Englisch (nach Huddleston/Pullum (Hg.) 2002: 1677 ff.)

Präfixe:

a-, after-, anti-, be-, counter-, dis-, em-, en-, ex-, fore-, im-, in-, inter-, ir-, micro-, mid-, non-, out-, over-, post-, pre-, sub-, super-, trans-, un-, under-

Suffixe:

-able, -age, -al, -an, -ance, -ant, -ar, -ate, -atic, -cy, -dom, -ed, -ee, -eer, -en, -ence, -ent, -eous, -er, -ery, -ese, -ess, -est, -et, -ette, -ety, -ful, -hood, -i, -ial, -ian, -ible, -ic, -ie, -ify, -ine, -ing, -ion, -ious, -ish, -ism, -ist, -ite, -ity, -ive, -ize, -less, -let, -like, -ling, -ly, -ment, -ness, -or, -ory, -ous, -ry, -s, -’s, -ship, -some, -ster, -th, -ty, -ual, -ure, -y 


\section{Anhang B: Absolute Häufigkeiten der Buchstaben im Korpus}

Absolute Häufigkeiten der Buchstaben in den CELEX-Teilkorpora einfacher deutscher Stämme und einfacher englischer Stämme.

\begin{tabular}{|c|c|c|}
\hline Buchstabe & Frequenz de & Frequenz en \\
\hline $\mathrm{a}$ & 2.371 & 3.477 \\
\hline ä & 167 & \\
\hline b & 785 & 943 \\
\hline c & 1.041 & 1.763 \\
\hline d & 659 & 1.111 \\
\hline e & 4.034 & 4.045 \\
\hline$f$ & 624 & 658 \\
\hline g & 751 & 984 \\
\hline $\mathrm{h}$ & 1.432 & 1.277 \\
\hline i & 1.744 & 2.254 \\
\hline j & 88 & 116 \\
\hline k & 1.176 & 608 \\
\hline 1 & 1.974 & 2.376 \\
\hline $\mathrm{m}$ & 1.110 & 1.246 \\
\hline $\mathrm{n}$ & 1.819 & 2.146 \\
\hline 0 & 1.150 & 2.623 \\
\hline$\ddot{0}$ & 104 & \\
\hline $\mathrm{p}$ & 965 & 1.352 \\
\hline$q$ & 34 & 128 \\
\hline$r$ & 2.386 & 2.652 \\
\hline s & 1.971 & 2.238 \\
\hline B & 45 & \\
\hline $\mathrm{t}$ & 2.031 & 2.448 \\
\hline $\mathrm{u}$ & 1.082 & 1.525 \\
\hline$\ddot{u}$ & 201 & \\
\hline v & 162 & 377 \\
\hline w & 341 & 524 \\
\hline$x$ & 48 & 108 \\
\hline y & 73 & 389 \\
\hline$z$ & 404 & 151 \\
\hline
\end{tabular}




\section{Anhang C: Kreuztabellen der Minimalpaare}

Kreuztabelle der Minimalpaare im Korpus deutscher Stämme

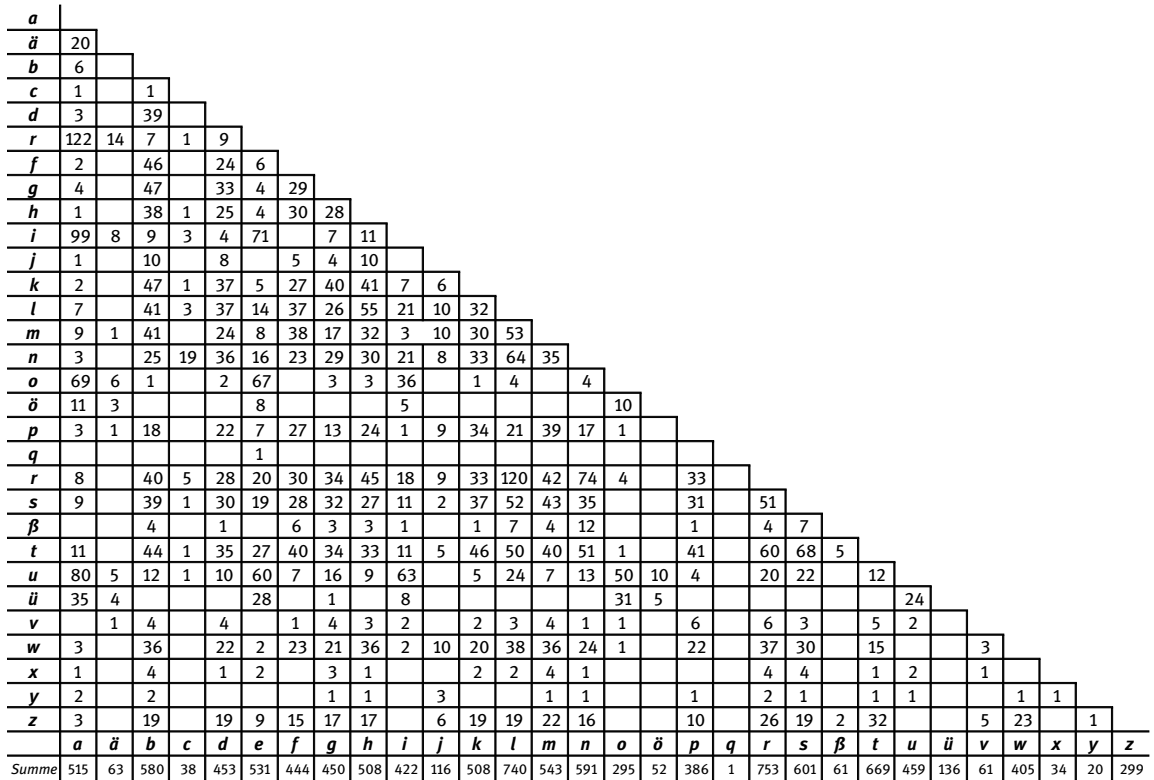


Kreuztabelle der Minimalpaare im Korpus englischer Stämme

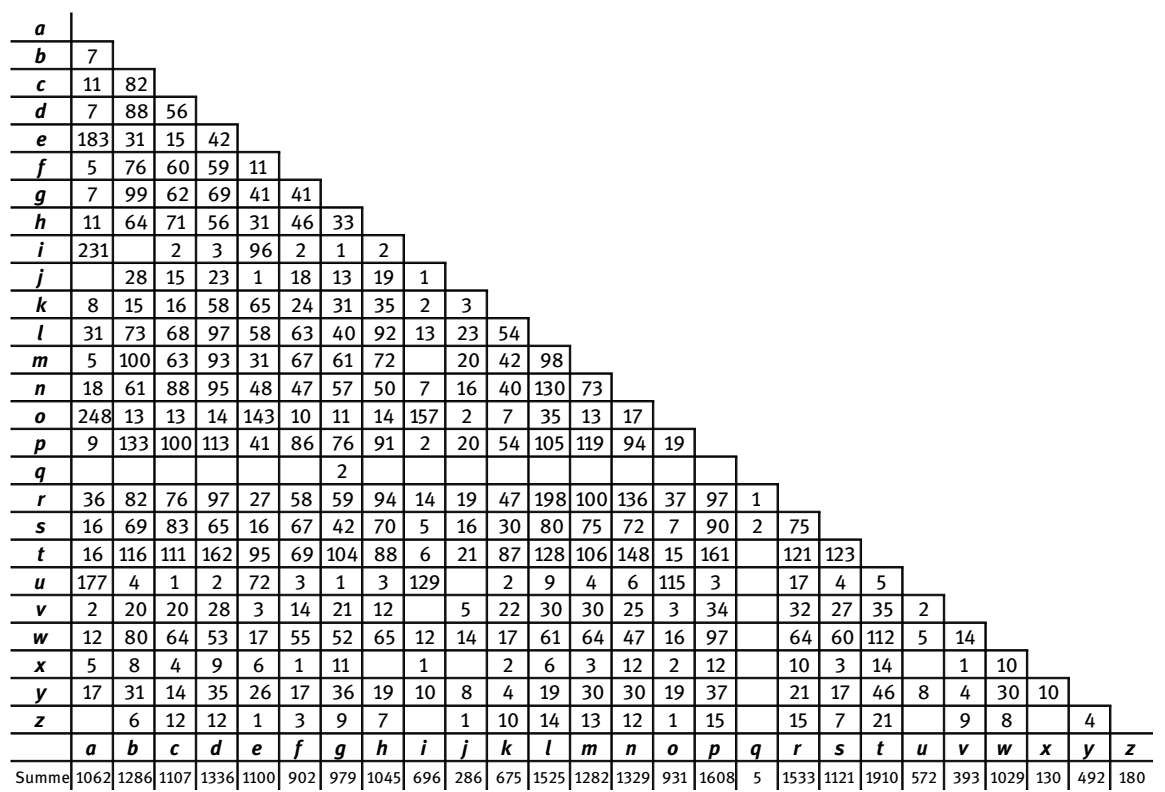

